\title{
PENGARUH PENDIDIKAN AGAMA ISLAM DALAM KELUARGA TERHADAP SIKAP BERAGAMA SISWA
}

\author{
St. Rajiah Rusydi ${ }^{1}$, Alamsyah ${ }^{2}$ \\ ${ }^{* 1}$ Pendidikan Agama Islam Fakultas Agama Islam| Unismuh Makassar \\ ${ }^{*}$ Pendidikan Agama Islam Fakultas Agama Islam| Unismuh Makassar
}

\begin{abstract}
ABSTRAK
Jenis penelitian ini merupakan penelitian survey dan merupakan jenis penelitian deskriptif kualitatif. Populasi dalam penelitian ini adalah semua siswa dan orang tua siswa. Adapun teknik yang digunakan adalah teknik penarikan sampel secara Porposive Sampling yakni sampel diambil secara langsung yaitu kelas I, II, III yang berjumlah 134 siswa dan sampel pada siswa dikhususkan kepada proses pembelajaran Pendidikan Agama Islam sehingga langsung kepada guru yang mengajar Pendidikan Agama Islam. Selanjutnya data yang dikumpulkan di lapangan diolah dengan analisis deskriptif kuantitatif. Dari hasil penelitian membuktikan bahwa, pengaruh pendidikan agama islam dalam keluarga terhadap sikap beragama siswa di Madrasah Aliyah Darunnajah Botong Kec. Bungaya Kab, Gowa adanya kompetensi kepribadian yang dimiliki oleh guru Pendidikan Agama Islam dan keluarga, siswa dapat belajar dengan efektif dan suasana yang kondusif, bersikap baik terhadap guru Pendidikan Agama Islam dan orang tua, siswa mampu menerima pelajaran dengan baik sehingga siswa bisa menambah pengetahuannya terkhusus dalam mata pelajaran Pendidikan Agama Islam yang berpengaruh terhadap akhlak dan tingkah laku siswa di dalam keluarga.
\end{abstract}

Kata Kunci : Pendidikan Agama Islam, Keluarga dan Beragama siswa

\begin{abstract}
This type of research was a survey research and was a descriptive qualitative research. The population in this study were all students and parents of students. The technique used was sampling technique in Porposive Sampling ie the sample is taken directly that is class I, II, III which amounted to 134 students and the sample on the students was devoted to the learning process of Islamic Religious Education so directly to teachers who teach Islamic Religious Education. Further data collected in the field is processed by quantitative descriptive analysis. From the research results prove that, the influence of religious education in the family of religious attitudes toward students in Madrasah Aliyah Darunnajah Botong Kec. Bungaya Kab, Gowa presence of personality competencies owned by teachers of Islamic Religion and family, students can learn effectively and conducive atmosphere, be kind to teachers of Islamic Education and parents, students are able to receive lessons well so that students can increase their knowledge especially in the subjects of Islamic Religious Education which affect the character and behavior of students in the family.
\end{abstract}

Keywords: Islamic Education, Family and Religious Students 


\section{PENDAHULUAN}

Pendidikan adalah usaha sadar yang dilakukan oleh keluarga, masyarakat dan pemerintah, melalui kegiatan bimbingan, pengajaran, dan latihan, yang berlangsung di sekolah dan di luar sekolah sepanjang hayat, untuk mempersiapkan peserta didik agar dapat memaikan peranan dalam berbagai lingkungan hidup secara tepat di masa yang akan datang. Pendidikan adalah pengalaman-pengalaman belajar terprogram dalam bentuk pendidikan formal dan non formal, dan informal di sekolah, dan di luar sekolah, yang berlangsung seumur hidup yang bertujuan optimalisasi pertimbangan kemampuankemampuan individu, agar di kemudian hari dapat memainkan peran hidup secara tepat".

Pendidikan sebagai sebuah bentuk kegiatan manusia dalam kehidupannya juga menempatkan tujuan sebagai sesuatu yang hendak dicapai, baik tujuan yang dirumuskan itu bersifat abstrak sampai rumusanrumusan yang dibentuk secara khusus untuk memudahkan pencapaian tujuan yang lebih tinggi. Begitu juga dikarenakan pendidikan merupakan bimbingan terhadap perkembangan manusia menuju kearah cita-cita tertentu, maka yang

Dalam perkembangannya pendidikan berarti bimbingan atau pertolongan yang diberikan secara sengaja terhadap anak didik oleh orang dewasa agar anak didik menjadi dewasa, dalam perkembangan selanjutnya, pendidikan berarti usaha yang dijalankan oleh seseorang atau sekelompok orang agar menjadi dewasa atau mencapai tingkat hidup dan penghidupan yang lebih tinggi dalam arti mental. Dengan demikian pendidikan berartisegala usaha orang dewasa dalam pergaulannya dengan anak-anak untuk memimpin perkembangan jasmani dan rohaninya kearah kedewasaan.

Orang tua sebagai penanggung jawab dalam keluarga tidak dapat disalahkan begitu saja. Adanya kesibukan orang tua dalam mencari nafkah, bekerja, dan lain-lain merupakan suatu hal yang wajar dalam kehidupan sosial manusia demi untuk kebutuhan keluarganya, Namun, apa yang dilakukan oleh orang tua tentunya tidak harus melepaskan tanggung 
jawabnya sebagai pembimbing dan pendidik dalam rumah tangga.

Keluarga sebagai lembaga pendidikan pertama dan utama seharusnya memberikan pembinaan akhlak, perhatian, arahan, dan bimbingan lkepda anak-anaknya yang disesuaikan dengan tingkat pertumbuhan dan perkembangannya. Dalam hal ini pendidikan islam menempatkan orang tua sebagai pendidik utama dan pertama. Keluarga adalah salah satu elemen pokok pembangunan entitas pendidikan, menciptakan proses naturalisasi social, membentuk kepribadian, serta member berbagai kebiasaan baik pada anakanak yang terus bertahan selamanya. Dengan kata lain, keluarga merupakan benih awal penyusunan kematangan individu dan struktur kepribadian. Dalam banyak kasus, untuk mengikuti orang itu dalam berbagai kebiasaan dan perilaku. Keluarga merupakan lembaga istitusi pendidikan yang paling nyata pengaruhnya terhadap pembetukan akhlas dan moral anak. Berdasarkan latar belakang diatas maka selanjutnya penulis merumuskan masalah yang di anggap perlu untuk dikaji lebih lanjut. Adapun rumusan masalah yang dimaksud adalah sebagai berikut :

1. Bagaimana pengaruh pendidikan agama islam dalam keluarga dalam sikap beragama siswa di Madrasah Aliyah Darunnajah Botong Kecamatan Bungaya Kabupaten Gowa?

2. Usaha-usaha apa yang dilakukan dalam meningkatkan Sikap Beragama Siswa di Madrasah Aliyah Darunnajah Botong Kecamatan Bungaya Kabupaten Gowa?

\section{METODE PENELITIAN}

Jenis penelitian adalah yang digunakan oleh peneliti adalah penelitian survey dan merupakan penilitian kualitatif dengan mengoksplorasikan data di lapangan dengan metode analisis deskriktif yang bertujuan memberikan gambaran secara cepat tepat tentang pengaruh pendidikan Agama Islam Dalam Keluarga Terhadap Sikap Beragama Siswa Di MA Darunnajah Botong Kec.Bungaya Kab. Gowa.

Metode kualitatif sebagai prosedur peniliti yang menghasilkan data 
kualitatif yang berupa ungkapan atau catatan orang itu sendiri atau tingkah laku mereka yang terobsesi. Pada sisi lain, Kirk dan Miller (1995, 60) mendifinisikan bahwa penelitian kualitatif adalah tradisi tertentu dalam ilmu pengetahuan sosial yang secara fundamental tergantung pada pengamatan manusia dalam kawasannya sendiri dan berhubungan dengan orang-orang tersebut dalam bahasa dan peristilahannya

\section{Tabel I}

Jumlah Populasi Siswa dan Orang tua

\begin{tabular}{|c|c|c|c|c|}
\hline No & $\begin{array}{c}\text { Siswa dan } \\
\text { orang tua } \\
\text { siswa }\end{array}$ & LK & PR & Jumlah \\
\hline 1. & $\begin{array}{c}\text { Siswa } \\
\text { kelas I }\end{array}$ & 6 & 10 & 16 \\
\hline 2. & $\begin{array}{c}\text { Siswa } \\
\text { kelas II }\end{array}$ & 7 & 15 & 22 \\
\hline 3. & $\begin{array}{c}\text { Siswa } \\
\text { kelas III }\end{array}$ & 10 & 20 & 30 \\
\hline 4. & $\begin{array}{c}\text { Orang tua } \\
\text { siswa }\end{array}$ & 33 & 33 & 66 \\
\hline 5. & \multicolumn{2}{|c|}{56} & 78 & 134 \\
\hline \multicolumn{3}{|c|}{ Sumber Data : Kantor Madrasah Aliyah } \\
Darunnajah Botong 2015
\end{tabular}

Tabel II

Jumlah sampel siswa, dan Orang tua

\begin{tabular}{|c|c|c|c|c|}
\hline 2. & Kelas II & 1 & 2 & 3 \\
\hline 3. & Kelas III & 2 & 3 & 5 \\
\hline 4. & $\begin{array}{c}\text { Orang tua } \\
\text { siswa }\end{array}$ & 5 & 5 & 10 \\
\hline
\end{tabular}

Teknik pengumpulan data dalam penelitian ini, peneliti menggunakan beberapa teknik / metode antara lain : Observasi, Angket, Interview dan (wawancara) Dokumentasi. Penelitian ini merupakan deskriptif dengan menggunakan data kualitatif, lalu dianalisis dengan menggunakan teknik induktif untuk melihat persentase kecenderungan variabel penelitian sesuai dengan rumus yang diungkapkan oleh Suharsimi Arikunto (2000; 246) sebagai berikut :

$$
P=\frac{f}{N} \quad x \quad 100 \%
$$

Keterangan :

$\mathrm{F}$ = Frekuensi / banyaknya individu

$\mathrm{N}=$ Jumlah Frekuensi banyaknya individu

$\mathrm{P}=$ Angka Persentase

\begin{tabular}{|c|c|c|c|c|}
\hline No & $\begin{array}{c}\text { Siswa, } \\
\text { dan orang } \\
\text { tua }\end{array}$ & LK & PR & Jumlah \\
\hline 1. & Kelas I & 1 & 1 & 2 \\
\hline
\end{tabular}

HASIL DAN PEMBAHASAN PENELITIAN 
Pengaruh Pendidikan Agama Islam

Dalam Keluarga Terhadap Sikap Beragama Siswa

Berdasarkan uraian tersebut di atas, maka untuk mengetahui tentang pengaruh pendidikan agama islam dalam keluarga terhadap sikap beragama siswa yang ada pada Madrasah Aliyah Darunnajah Botong Kecamatan Bungaya Kabupaten Gowa dapat di lihat pada tabel berikut :

Tabel III

Daftar Distribusi Frekuensi Tanggapan Responde tentang pengaruh PAI

\begin{tabular}{|c|l|c|c|}
\hline No & \multicolumn{1}{|c|}{ Jawaban } & $\begin{array}{c}\text { Frekuen } \\
\text { si }\end{array}$ & $\begin{array}{c}\text { Perse } \\
\text { ntase } \\
(\%)\end{array}$ \\
\hline 1 & Sangat sering & 7 & $33 \%$ \\
\hline 2 & Sering & 2 & $25 \%$ \\
\hline 3 & Kadang-kadang & 1 & $42 \%$ \\
\hline 4 & Tidak Pernah & - & - \\
\hline \multicolumn{2}{|c|}{ Jumlah (N) } & 10 & $100 \%$ \\
\hline
\end{tabular}

Sumber data : Hasil tabulasi angket item nomor 1

Dari data di atas diketahui bahwa ada 12 siswa atau $50 \%$ yang menjawab bahwa guru dan keluarga dalam memberikan pengetahuan dan kepribadian pada siswa, 3 siswa atau $25 \%$ yang menjawab sering, 8 siswa atau $42 \%$ yang menjawab kadangkadang, 1 siswa yang menjawab kurang atau 4\%, dan 0 siswa yang menjawab tidak pernah. Jadi, data tersebut di atas menunjukkan bahwa guru dan keluarga kadang-kadang memberikan pengetahuan dan kepribadian pada siswa.

\section{Tabel VI}

Responden tentang keluarga dan Guru PAI dalam mengingatkan pada siswa untuk menjalankan kewajiban sebagai umat islam

\begin{tabular}{|c|c|c|c|}
\hline No & Jawaban & $\begin{array}{c}\text { Frekue } \\
\text { nsi }\end{array}$ & $\begin{array}{c}\text { Persenta } \\
\text { se }(\%)\end{array}$ \\
\hline 1 & $\begin{array}{l}\text { Sangat } \\
\text { sering }\end{array}$ & 5 & $50 \%$ \\
\hline 2 & Sering & 5 & $50 \%$ \\
\hline 3 & $\begin{array}{l}\text { Kadang- } \\
\text { kadang }\end{array}$ & - & - \\
\hline 4 & $\begin{array}{l}\text { Tidak } \\
\text { Pernah }\end{array}$ & - & - \\
\hline \multicolumn{2}{|c|}{ Jumlah (N) } & 10 & $100 \%$ \\
\hline
\end{tabular}

bahwa ada 18 siswa atau $80 \%$ yang menjawab bahwa orang tua dan guru Pendidikan Agama Islam sangat sering mengingatkan untuk menjalankan kewajiban sebagai umat islam, 2 siswa 
atau $80 \%$ yang menjawab sering, 0 siswa yang menjawab kadang-kadang, 0 siswa yang menjawab kurang, dan 0 siswa yang menjawab tidak pernah. Jadi, data tersebut di atas menunjukkan bahwa orang tua guru Pendidikan Agama Islam sangat sering mengingatkan untuk menjalankan kewajiban sebagai umat islam pada siswa.

\section{Tabel V}

Responden terhadap keluarga dan

Guru PAI selalu mengingatkan pada siswa ketika melakukan kesalahan

\begin{tabular}{|c|c|c|c|}
\hline No & $\begin{array}{l}\text { Alternatif } \\
\text { Jawaban }\end{array}$ & $\begin{array}{c}\text { Frekue } \\
\text { nsi }\end{array}$ & $\begin{array}{l}\text { Persent } \\
\text { ase }(\%)\end{array}$ \\
\hline 1 & Sangat sering & 5 & $50 \%$ \\
\hline 2 & Sering & 3 & $35 \%$ \\
\hline 3 & $\begin{array}{l}\text { Kadang- } \\
\text { kadang }\end{array}$ & 2 & $15 \%$ \\
\hline 4 & Tidak Pernah & - & - \\
\hline \multicolumn{2}{|c|}{ Jumlah (N) } & 10 & $100 \%$ \\
\hline
\end{tabular}

Sumber data : Hasil tabulasi angket item nomor 3

Dari data di atas diketahui bahwa ada 12 siswa atau $50 \%$ yang menjawab bahwa orang tua dan guru Pendidikan Agama Islam selalu mengingatkan pada siswa ketika melakukan kesalahan, 9 siswa atau 50 $\%$ yang menjawab sangat sering, 8 siswa atau $35 \%$ yang menjawab sering, 1 siswa atau $15 \%$ yang menjawab kadang-kadang, 0 siswa yang menjawab kurang, dan 0 siswa yang menjawab tidak pernah. Jadi, data tersebut di atas menunjukkan bahwa orang tua dan guru Pendidikan Agama Islam selalu mengingatkan pada siswa ketika melakukan kesalahan.

Tabel VI

Responden tentang siswa paham saat mendapatkan pelajaran dari guru PAI

\begin{tabular}{|c|c|c|c|}
\hline No & $\begin{array}{c}\text { Jawab } \\
\text { an }\end{array}$ & $\begin{array}{c}\text { Freku } \\
\text { ensi }\end{array}$ & $\begin{array}{c}\text { Persentase } \\
(\%)\end{array}$ \\
\hline 1 & $\begin{array}{l}\text { Sangat } \\
\text { Paham }\end{array}$ & 6 & $10 \%$ \\
\hline 2 & Paham & 2 & $79 \%$ \\
\hline 3 & $\begin{array}{l}\text { Kadang } \\
\text { - } \\
\text { kadang }\end{array}$ & 2 & $11 \%$ \\
\hline 4 & $\begin{array}{l}\text { Tidak } \\
\text { Paham }\end{array}$ & - & - \\
\hline \multicolumn{2}{|c|}{ Jumlah (N) } & 10 & $100 \%$ \\
\hline
\end{tabular}

Dari data di atas diketahui bahwa ada 14 siswa atau $79 \%$ yang menjawab bahwa mereka paham ketika guru PAI memberikan pelajaran pada siswa ,1 siswa atau $10 \%$ yang menjawab sering, 3 siswa atau $11 \%$ yang menjawab kadang-kadang, 0 siswa menjawab kurang, dan 0 siswa 
menjawab tidak paham. Jadi, data tersebut di atas menunjukkan bahwa siswa sangat paham ketika guru PAI memberikan arahan di sekolah.

Tabel VII

Responden tentang Guru PAI yang Sering Menyapa Siswa

\begin{tabular}{|c|l|c|c|}
\hline No & \multicolumn{1}{|c|}{ Jawaban } & $\begin{array}{c}\text { Frek } \\
\text { uensi }\end{array}$ & $\begin{array}{c}\text { Persentase } \\
(\%)\end{array}$ \\
\hline 1 & Sangat sering & - & - \\
\hline 2 & Sering & 5 & $25 \%$ \\
\hline 3 & $\begin{array}{l}\text { Kadang- } \\
\text { kadang }\end{array}$ & 5 & $75 \%$ \\
\hline 4 & Tidak Pernah & - & - \\
\hline \multicolumn{2}{|c|}{ Jumlah (N) } & 10 & $100 \%$ \\
\hline
\end{tabular}

Sumber data : Hasil tabulasi angket item nomor 5

Dari data di atas diketahui bahwa ada 0 siswa yang menjawab bahwa siswa sangat sering menyapa siswa, 3 siswa atau $25 \%$ yang menjawab sering, 15 siswa atau $75 \%$ yang menjawab kadang-kadang, dan 0 siswa yang menjawab kurang dan tidak pernah. Jadi, data tersebut di atas menunjukkan bahwa Guru Pendidikan Agama Islam kadang-kadang menyapa siswa pada saat bertemu di sekolah maupun diluar sekolah.
Usaha-Usaha Yang Dilakukan

Dalam Meningkatkan Sikap

\section{Beragama Siswa}

Untuk mengetahui lebih jauh dapat dilihat melalui hasil angket yang diedarkan pada siswa. Angket yang berorientasi pada sikap beragama siswa terdiri dari 5 soal, hal ini dimaksud untuk melihat sejauh mana tumbuhnya kesadaran siswa dalam menciptakan suasana pembelajaran yang efektif, sebagaimana telah dikemukakan lebih awal. Dengan bertitik pada masing-masing soal angket tersebut, kemudian diolah dengan sistem persentase berdasarkan angket yang diedarkan pada 10 siswa responden sebagai sampel penelitian ini.

Pada dasarnya perubahan perilaku yang dapat ditunjukkan oleh peserta didik dipengaruhi oleh latar belakang pendidikan dan pengalaman yang dimiliki oleh seorang guru dan keluarga. Atau dengan perkataan lain, guru dan keluarga mempunyai pengaruh terhadap perubahan perilaku peserta didik. Guru dan keluarga harus dapat menjadi contoh (suri teladan) bagi peserta didik. Pengaruh pendidikan agama islam sangatlah 
berpengaruh terhadap suasana pembelajaran di kelas maupun diluar kelas karena peserta didik akan mencontoh perilaku yang ditunjukkan oleh seorang pendidik. Pengaruh pendidikan agama islam yang baik, dapat terwujud apabila seorang guru dan keluarga kreatif dan profesional dalam proses pembelajaran, seperti berikut :

1. Guru dan keluarga perhatian terhadap siswanya. Apabila seorang siswa mengalami kesulitan dalam pelajaran, guru akan membantu siswa dengan sepenuh hati tanpa ada rasa bosan untuk membimbing dan mendidik siswa.

2. Seorang guru dan keluarga yang baik, mampu menjadi motivator terhadap siswanya. Karena dengan motivasi yang diberikan kepada siswa, akan membantu siswa lebih rajin belajar dan meningkatkan prestasi yang dimilikinya.

3. Guru dan keluarga yang pengertian akan disenangi oleh siswa. Karena dia mampu memahami apa yang diinginkan oleh siswa, sehingga kontak batin antara siswa dan guru akan terjalin dengan sendirinya.

4. Seorang guru dan keluarga harus bersikap lemah lembut dan penuh kasih sayang terhadap siswa.

5. Guru dan keluarga harus memberikan senyum kepada siswa. Karena senyum yang tulus dari seorang guru akan disenangi oleh siswanya, motivasi belajar siswa pun akan tinggi, karena keakraban antara guru, orang tua dan siswa akan terjalin.

6. Guru dan keluarga yang berpenampilan indah dan rapi akan menjadi teladan bagi siswa, dan cenderung akan disenangi oleh siswa. Hal ini dikarenakan sesuatu yang indah akan membuat seseorang senang untuk melihatnya.

7. Seorang guru dan keluarga harus berakhlak mulia, karena siswa akan mencontoh setiap kebiasaan, sifat, dan perilaku seorang guru. Karena guru adalah cerminan bagi siswanya.

\section{KESIMPULAN}


Berdasarkan uraian di atas penulis dapat menyimpulkan bahwa pengaruh pengaruh pendidikan agama islam dalam keluarga terhadap sikap beragama siswa merupakan perwujudan pengalaman terhadap agama yang menyangkut persoalan batin seseorang karena sikap beragama pun tidak bisa di pisahkan dari ketaatan seseorang terhadap agamanya sendiri.

1. Pembentukan sikap dan perubahan sikap dipengaruhi oleh dua faktor yaitu :

a. Faktor internal yaitu berupa kemampuan menyeleksi dan menganalisis pengaruh yang datang dri luar termasuk minat dan perhatian. Pada dasarnya manusia lahir dalam keadaan fitrah (potensi beragama), hanya faktor lingkungan (orang tua) yang mempengaruhi

perkembangan fitrah

beragama anak.

b. Faktor eksternal, berupa faktor diluar individu yaitu pengaruh lingkungan yang diterima. Faktor eksternal adalah manusia memiliki potensi dasar yang dapat dikembangkan sebagai mahkluk yang beragama. Potensi yang dimiliki manusia secara umum disebut fitrah yang beragama.

2. Usaha dalam Pendidikan Agama Islam dalam sikap beragama siswa di Madrasah Aliyah Darunnajah Botong kec. Bungaya Kab. Gowa dikatakan efektif, karena guru dan keluarga mampu menerapkan pengetahuan terhadap siswa dan guru beserta keluarga mampu memberikan pengetahuan yang dimilikinya dan diteladani dengan baik oleh peserta dididik.

\section{DAFTAR PUSTAKA}

Ahmad Tafsir, Pendidikan Agama Islam dalam Keluarga : Bandung : Remaja Rosdakarya, 1996.

Ali, Muhammad Daud, Pendidikan Agama Islam, Jakarta: PT Raja Grafindo Persada, 2008.

Aly, Hery Noer, Ilmu Pendidikan Islam, Jakarta : Logos, 1999

An-Nahlawi, Abdurahman. Ushulut Tarbiyah Islamiyah Wa Asalibiha Fil Baiti Wal Madrasati Wal Mujtama'terj. Sihabuddin Pendidikan Islam 
Dalam Keluarga Di Sekolah Dan Masyarakat, Bandung: Diponegoro, 1992.

Ash Swhiddieqy, Teungku Muhammad Hasbi. Sejarah Dan Pengantar Ilmu Al-Qur'an dan Tafsir, Semarang : Pustaka Rizki Putra, 2000.

Baqir Shafit Al Qarashi, The Education In Islam, Terjemahan Mustafa Budi Santoso, Dengan Judul “ Seni Mendidik Islam. Jakarta: Pustaka Zahra,, 2005

Chaeruddin B, Metodologi Pengantar Agama Islam Luar Sekolah, Yogyakarta: Lanarka, 2009.

Departemen Agama RI, Tentang AlQur'an dan Terjemahan, 2013.

Ilyas, Asnelly. Mendambakan Anak Saleh : Prinsip-Prinsip Pendidikan Anak Dalam Islam, Bandung : Al-Bayan, 1996.

Jalaluddin, Teologi Pendidikan, Jakarta : Raja Grafindo Persada, 2001.

Ni'am, Munawir. Undang-Undang Sistem Pendidikan Nasiaonal, Yogyakarta: Media Wacana Press, 1992.

Pujosuwarno, Sayekti. Bimbingan Konseling Keluarga, Yogyakarta: Menara Mas Offset, 1994.

Ramayulis Tuanku Khatib, Pendidikan Islam Dalam Rumah Tangga, Jakarta: Kalam Mulia, 2001.
Siti Vembrianto, Sosiologi Pendidikan, Jakarta: Gramedia, 1993.

Shochib, Moh. Pola Asuh Orang Tua, Cet 1; Jakarta: PT. Rineka Cipta, 2002.

Sujanto, Agus. Psikologi Perkembangan, Jakarta : Rineka Cipta: 1996.

Tafsir, Ahmad. Pendidikan Agama Islam Dalam Keluarga, Cet 1; Bandung: Remaja Rosdakarya Offset, 1996.

Ulwan, Abdullah Nasih, Pendidikan Anak Menurut Islam Pemeliharaan Kesehatan Jiwa Anak, Bandung: Remaja Rosdakaya, 1990.

Yusuf, Samsul, Psikologi Perkembangan Anak Dan Remaja, Jakarta: Remaja Rosdakarya, 2000.

Zakiah Daratjad, Ilmu Pendidikan Islam, Jakarta : Bumi Aksara, 1996.

Zuhairini, Pilsafat Pendidikan Islam, Cet IV; Jakarta: Bumi Aksara, 2008. 